\title{
Improvement of the sensitivity of a conductometric soot sensor by adding a conductive cover layer
}

\author{
P. Bartscherer ${ }^{1}$ and R. Moos $^{2}$ \\ ${ }^{1}$ Robert Bosch GmbH, Robert-Bosch-Platz 1, 70839 Gerlingen-Schillerhöhe, Germany \\ ${ }^{2}$ Bayreuth Engine Research Center (BERC), University of Bayreuth, 95447 Bayreuth, Germany \\ Correspondence to: R. Moos (functional.materials@uni-bayreuth.de)
}

Received: 22 February 2013 - Revised: 2 June 2013 - Accepted: 4 June 2013 - Published: 3 July 2013

\begin{abstract}
Diesel particulate filters are emission-relevant devices of the exhaust gas aftertreatment system. They need to be monitored as a requirement of the on-board diagnosis. In order to detect a malfunction, planar sensors with interdigital electrodes on an insulating substrate can be installed downstream of the filter. During the loading phase, soot deposits onto the electrodes, but the sensor remains blind until the percolation threshold has been reached (initiation time) and the sensor current starts to flow. In order to detect small soot concentrations downstream of the filter from small defects, this initiation time needs to be as low as possible. One may reduce the initiation time by covering the interdigital electrodes with an electrically conductive layer. Using finite element method (FEM) simulations, the influence of conductivity and thickness of such a coating on the initiation time are determined. It is found that a thin, screen printable coating with a thickness of $20 \mu \mathrm{m}$ and a conductivity in the range of $10^{-3}$ to $10^{-1} \mathrm{~S} \mathrm{~m}^{-1}$ may reduce the initiation time by about $40 \%$. The FEM results were verified by a commercially available thick film resistor paste with a conductivity of $0.45 \mathrm{mS} \mathrm{m}^{-1}$, showing an improvement of about $40 \%$ compared to an uncoated sensor.
\end{abstract}

\section{Introduction}

Together with the constantly tightening limits of harmful exhaust gas emissions of internal combustion engines, a permanent monitoring of all emission-relevant devices is required (Europäisches Parlament, 2007; European Union, 2008). For Diesel engines, $\mathrm{NO}_{\mathrm{x}}$ abatement and particulate matter (PM) reduction are of special importance (Johnson, 2007; Twigg, 2007). PM consists of aggregated carbon soot particles, covered with organics like (polycyclic aromatic) hydrocarbons, and inorganic oxides (e.g., ashes originating from wear of the engine or engine oil additives) (Spears, 2008; U.S. Environmental Protection Agency, 2002). Not only due to the small size of these particles, ranging between only a few tens and some hundreds of nanometers (Harris and Maricq, 2001), but also because of the soluble organic fraction (SOF) covering the surface of these small particles (Otto et al., 1980; U.S. Environmental Protection Agency, 2002), serious concerns exist about the effect of PM to human health (Geiser, 2005; Adar et al., 2010; Grahame and Schlesinger, 2010; U.S. Environmental Protection Agency, 2002).
In order to reduce the mass and the number of PM in the exhaust, diesel particulate filters (DPF) - typically porous ceramic wall-flow filters (Fino, 2007; Twigg and Phillips, 2009) - are installed in the exhaust line. When soot is deposited in the filter, the pores get clogged and the exhaust backpressure increases with increasing soot load (Alkemade and Schumann, 2006; Duvinage et al., 2001). Therefore, the DPF must be regenerated from time to time, typically by heating the filter to several hundred ${ }^{\circ} \mathrm{C}$ and oxidizing the soot. Currently the approach is to use the pressure difference up- and downstream of the DPF together with an engine map-oriented soot load model to estimate the soot load and the point in time when the regeneration needs to be initiated (Alkemade and Schumann, 2006; Rose and Boger, 2009). Recent research ideas try to determine the soot content by measuring the electrical impedance of the DPF itself during operation (Feulner et al., 2013) or by evaluating the soot load-dependent perturbation of the electrical resonance behavior in the $\mathrm{GHz}$ range (Moos et al., 2013; Fischerauer et al., 2010). 


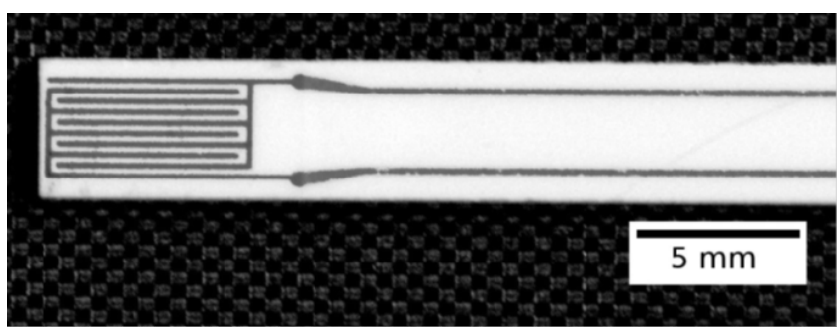

Figure 1. Image of an uncoated blank sensor with interdigital electrodes (IDEs) and feed lines.

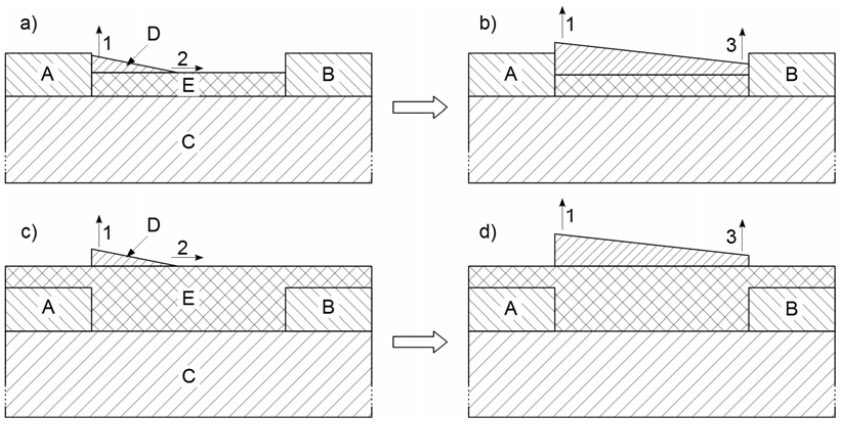

Figure 2. Geometry used for the simulations. The upper row (a and b) depicts the setup for a coating (E) being thinner than the electrodes (A) and (B). The lower row (c and d) depicts the case of a coating $(\mathrm{E})$ being thicker than the electrodes (coating covers the electrodes). 1, 2 and 3 indicate the growth direction of the soot path (D). C indicates the electrically insulating substrate.

The first method is serial standard, but it has not been clarified yet whether this method is precise enough to detect reliably small malfunctions of DPFs, like small cracks or holes that lead to soot slip. Therefore, sensors measuring the amount of soot in the exhaust downstream of a DPF are in discussion. Many principles for such sensors have been investigated, but the conductometric approach is considered the best choice for PM detection, especially with respect to the low-cost of a sensor (Riegel and Klett, 2008). A typical conductometric PM sensor is shown in Fig. 1. It consists of two electrodes that are typically applied as interdigital electrodes (IDEs) on an electrically insulating substrate. Recent approaches are given by Ochs et al. (2010), Lloyd Spetz et al. (2012), Groß et al. (2012), Hagen et al. (2010), Bartscherer et al. (2007), Bartscherer and Schmidt (2008), or Bartscherer et al. (2008).

Soot is deposited by thermophoresis on the IDE structure. If a voltage is applied between both electrodes, electrophoresis also occurs. It even prevails over the thermophoretic effect.

If one neglects the substrate conductivity, the current does not flow before the first percolation path forms between the electrodes. In other words, the sensor remains "blind" at the beginning of a loading cycle. This blind time as well as the
Table 1. Electrical conductivities of the conductive layer in $\mathrm{mS} \mathrm{m}^{-1}$ used for different layer thicknesses and base currents/resistances.

\begin{tabular}{rrrrrrr}
\hline \multicolumn{2}{c}{$\begin{array}{c}\text { Wanted sensor } \\
\text { properties }\end{array}$} & & \multicolumn{3}{c}{$\begin{array}{c}\text { Conductivity for different thickness } \\
b \text { of the conductive layer }\end{array}$} \\
\cline { 1 - 4 } \cline { 5 - 7 }$R_{\text {nosoot }}$ & $I_{\text {no soot }}$ & & $1 \mu \mathrm{m}$ & $11 \mu \mathrm{m}$ & $20 \mu \mathrm{m}$ & $40 \mu \mathrm{m}$ \\
\hline $300 \mathrm{k} \Omega$ & $0.1 \mathrm{~mA}$ & & 9.01 & 0.82 & 0.46 & 0.25 \\
$30 \mathrm{k} \Omega$ & $1 \mathrm{~mA}$ & & 90.09 & 8.19 & 4.61 & 2.49 \\
$3 \mathrm{k} \Omega$ & $10 \mathrm{~mA}$ & & 900.90 & 81.93 & 46.08 & 24.96 \\
\hline
\end{tabular}

initiation time increases with decreasing PM concentration. Therefore, it will take some time to detect a DPF defect, especially for very small defects with very low soot concentration downstream of the DPF. To overcome this and to reduce the blind time, we suggest applying an electrically conductive layer that connects both electrodes and covers all the space in between them. By adding such a layer, a sootdependent current can be measured even if no soot percolation paths have reached the counter electrode.

It is the object of this study to demonstrate the feasibility of this idea. The first part of this article describes an FEM study to estimate suitable parameters with respect to conductivity and thickness of the conductive film. Later on, sensors coated with a commercial ruthenium oxide $\left(\mathrm{RuO}_{2}\right)$ based thick-film paste were used to verify the results of the simulations. $\mathrm{RuO}_{2}$ was only selected to prove the concept. For a reliable application in the exhaust, material with better long-term stability have to be applied.

\section{FEM Modeling}

\subsection{Setup and modeling}

One part of an IDE (as depicted in Fig. 2) was FEM modeled (FEM software Comsol Multiphysics). To comply with Fig. 1, the electrode width $(w)$ and spaces $(s)$ between the electrodes were set to $150 \mu \mathrm{m}$ each and the electrode thickness to $h=10 \mu \mathrm{m}$. The substrate thickness was set to $500 \mu \mathrm{m}$. Further elements of the sensor, like the embedded heater (Ochs et al., 2012), have not been considered in the model. All free edges of the sensors were set to an electric insulation (boundary condition). For the substrate conductivity, $10^{-12} \mathrm{~S} \mathrm{~m}^{-1}$ was assumed, which is a typical value for technical alumina at $200-400^{\circ} \mathrm{C}$ (Evans, 1995). Four different thicknesses $(b)$ of the conductive layer were modeled, each one with three different electrical conductivities (for values of the conductivities see Table 1). The conductivities were adjusted in a way that the basic current of the sensor without soot load, $I_{\text {nosoot }}$, was $0.1 \mathrm{~mA}, 1 \mathrm{~mA}$, or $10 \mathrm{~mA}$ at an applied voltage of $U=30 \mathrm{~V}$. Therefore, the conductivity for a thin layer had to be higher; the conductivity for a thicker layer had to be lower in order for the four different layers to exhibit the same base currents for the three different resistance levels. 


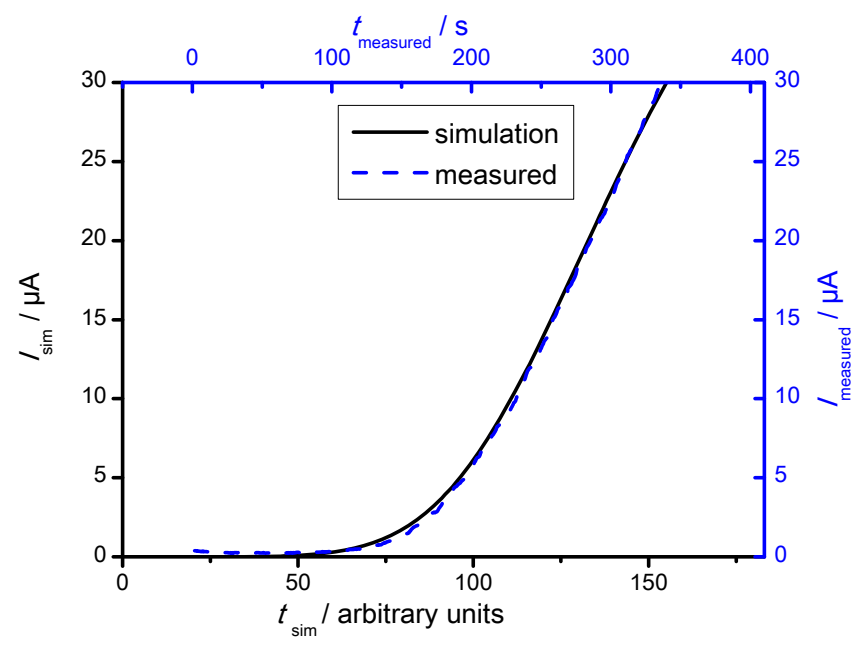

Figure 3. Simulation and real measurement of soot signal for a blank sensor.

Two geometries of the conductive layer have to be considered. In one case, the layer is thinner than the electrodes (i.e. $b<h=10 \mu \mathrm{m})$ and the electrodes are not covered by the applied conductive layer (Fig. 2a and b; top row). In this case, the soot can contact the electrodes directly. In the other case, the conductive layer is thicker than the electrodes $(b>h)$ and covers them (Fig. 2c and d; bottom row). In this case, soot has no direct contact to the electrodes.

Since there is not much known about the growth of soot paths in an electric field, some assumptions had to be made for the simulation. Light optical microscopy (Fig. 8) revealed that the soot paths are denser at one electrode - presumably at the electrode at which the growth is initiated - than on the other one. Therefore, the growing soot path was assumed to be wedge-shaped (D in Fig. 2), initially growing vertically at position 1 and horizontally at position 2 at the same time. When it reaches the counter electrode (position 3), it stops growing horizontally and the growth is vertical also at this position. From this point on, the the soot layer would contribute also to the current of a sensor without a conductive layer. At the end of the growth, the height of the wedge is $5 \mu \mathrm{m}$ at position 1 and $2.5 \mu \mathrm{m}$ at position 3 . Since the electrical conductivity of soot may vary with the type of soot, a macroscopic approach was conducted. A blank sensor without conductive layer but fully covered with soot shows a current of approximately $1 \mathrm{~mA}$, if a dc voltage of $30 \mathrm{~V}$ is applied to the electrode (at a sensor temperature of about $50^{\circ} \mathrm{C}$ ). This corresponds to a resistance of $30 \mathrm{k} \Omega$. The electrical conductivity of the soot in the simulations was chosen in a way that the resistance of the soot wedge amounted to this value at the end of the growth. Hence, the electrical conductivity of the soot should be about $25 \mathrm{mS} \mathrm{m}^{-1}$.

In reality, there is not only one soot path growing from one electrode to the other but instead many soot paths start to grow at different times. All paths are parallel connected

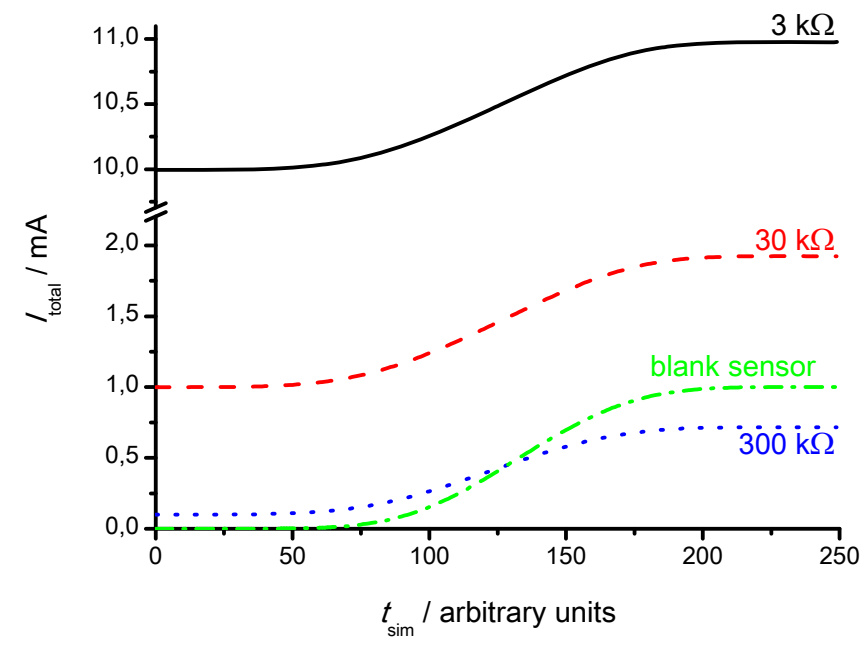

Figure 4. Simulation of the total current, $I_{\text {total }}$, for sensors with different conductive coatings leading to base resistances (without soot) of $3 \mathrm{k} \Omega, 30 \mathrm{k} \Omega$, and $300 \mathrm{k} \Omega$ (see Table 1) compared to a blank sensor. Coating thickness $b=11 \mu \mathrm{m}$.

and contribute to the total current according to their state of growth. To represent that, a Gaussian distribution (Eq. 1) of the number of paths, $n_{\text {paths }}$, starting to grow at a certain time, $t_{\mathrm{s}}$, in the simulation was assumed.

$n_{\text {paths }}\left(t_{\mathrm{s}}\right)=\frac{1}{25 \cdot \sqrt{2 \pi}} \cdot e^{-\frac{1}{2}\left(\frac{t_{\mathrm{s}}-75}{25}\right)^{2}} \cdot 15000$

Since the simulation should reveal only relative results for the different varied parameters, and due to the many uncertainties of the soot growth and its nature, the simulations have been done using arbitrary units for the time, $t_{\mathrm{s}}$. Different growth rates of the soot paths were not considered. Using this approach, only one path had to be calculated, but the output current of the whole sensor was obtained by superposing the currents of each single path according to the Gaussian distribution. Calculated and measured current progressions for a blank sensor without conductive layer agree quite well (Fig. 3) if one assumes appropriate scaling factors for current and time.

It should be annotated here that this model for the soot path growth does not consider the physical deposition mechanism of the soot. However, it will be shown that it is a very useful approximation that describes the current response quite well.

The measurement procedures for the experiments leading to Fig. 3 are described in the experimental Sect. 3.

\subsection{Variations of the layer parameters}

In the following, $I_{\text {total }}$ refers to the total current of a sensor, including the current through the conductive cover layer (if present) and the collected soot (the current through the substrate can be neglected because the substrate is insulating), and $I_{\text {no soot }}$ representing $I_{\text {total }}$ without collected soot. 


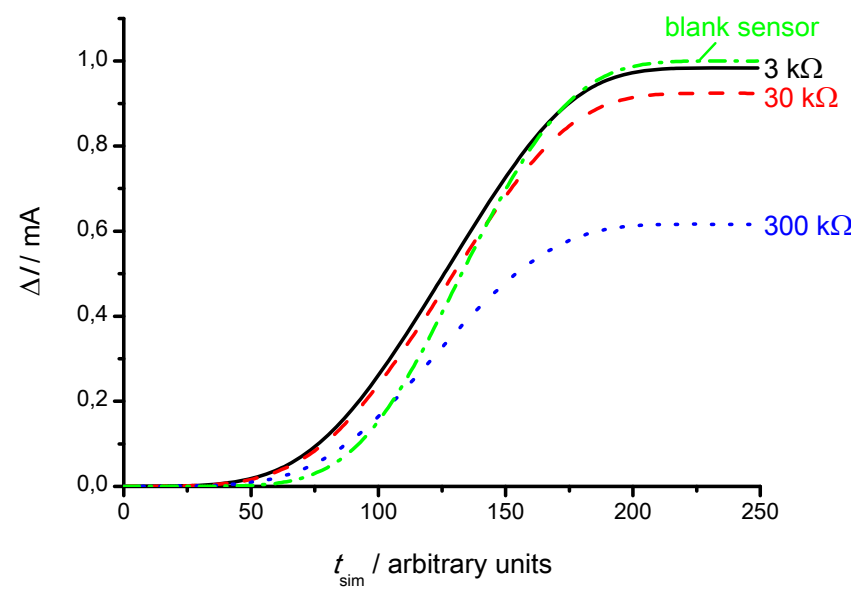

Figure 5. Current deviation $\Delta I=I_{\text {total }}-I_{\text {nosoot }}$, for coatings with base resistances (without soot) of $3 \mathrm{k} \Omega, 30 \mathrm{k} \Omega$ and $300 \mathrm{k} \Omega$, compared to a blank sensor. For raw data see Fig. 4.

Table 2. Total current and current deviation $\Delta I$ of a simulated conductive layer ( $b=11 \mu \mathrm{m}$ thickness) with different electrical conductivities.

\begin{tabular}{rrrr}
\hline$R_{\text {no soot }}$ & $I_{\text {no soot }}$ & $I_{\text {total }}$ & $\Delta I$ \\
\hline $300 \mathrm{k} \Omega$ & $0.1 \mathrm{~mA}$ & $0.716 \mathrm{~mA}$ & $616 \mu \mathrm{A}$ \\
$30 \mathrm{k} \Omega$ & $1 \mathrm{~mA}$ & $1.924 \mathrm{~mA}$ & $924 \mu \mathrm{A}$ \\
$3 \mathrm{k} \Omega$ & $10 \mathrm{~mA}$ & $10.977 \mathrm{~mA}$ & $977 \mu \mathrm{A}$ \\
\hline
\end{tabular}

Examples for the simulated total current, $I_{\text {total }}$, and the soot-related current deviation $\Delta I=I_{\text {total }}-I_{\text {nosoot }}$ for a blank sensor and sensors with a conductive layer of $b=11 \mu \mathrm{m}$ (see Fig. 2c and d) are shown in Figs. 4 and 5 for three different electrical conductivities in a way that $R_{\text {no soot }}$ corresponds to $3 \mathrm{k} \Omega, 30 \mathrm{k} \Omega$, or $300 \mathrm{k} \Omega$. Table 2 lists the numerical values. Figure 6 shows the magnification of Fig. 5 to extract the initiation time $t_{\mathrm{i}}$ for these four sensors at a trigger limit of $\Delta I_{\text {trigger }}=3 \mu \mathrm{A}$.

The differences in the total current arise from the different resistances of the conductive layers (as they depend on the cover layer materials conductivity and on the thickness of the cover layer), which add up to the resistance of the soot path. A low conductivity of the conductive layer yields high serial resistances, and therefore limits the current. It appears implausible at first glance that the current of the fully soot loaded but uncovered sensor (Fig. 4) should be higher than the $300 \mathrm{k} \Omega$-covered one. However, one has to consider that the conductive layer (which in case of a $300 \mathrm{k} \Omega$ layer exhibits poor conductivity) also covers the electrodes, prevents direct contact between soot and electrodes, and therefore limits the current.

The improvements that can be obtained with the conductive layers are summarized in Fig. 7 . Here, $\left(1-t_{\mathrm{i}} / t_{\text {ref }}\right) / \%$ indicates the percentaged reduction of the initiation time, $t_{\mathrm{i}}, \mathrm{com}$ pared to the initiation time, $t_{\text {ref }}$, of the uncoated blank sensor.

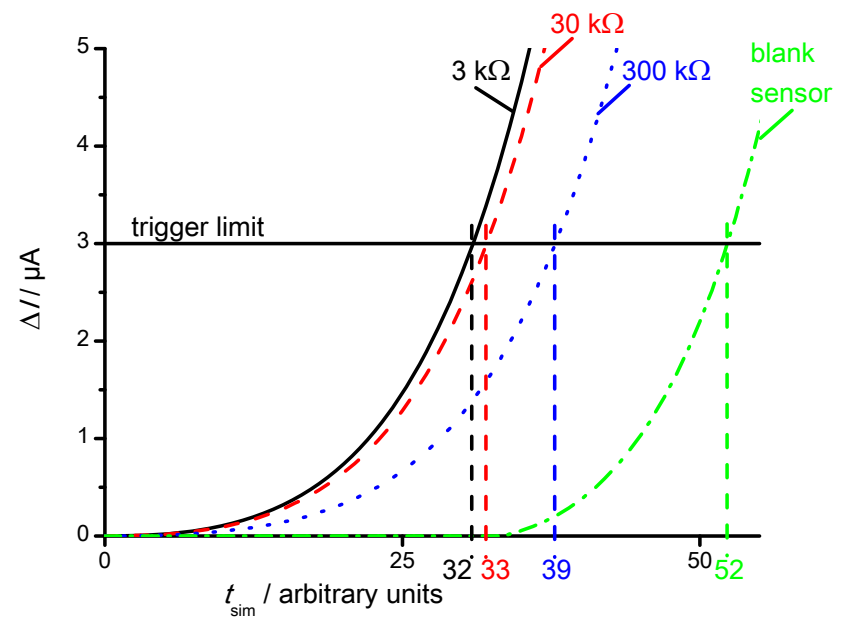

Figure 6. Magnification of Fig. 5 to determine the initiation time, $t_{\mathrm{i}}$, for coatings with different base resistances (without soot).

As shown by the simulations, an improvement of about $40 \%$ should be possible.

Thin layers with a high conductivity show the best performance, especially for the $1 \mu \mathrm{m}$ layer. Since such thin layers with $b<h$ (Fig. 2a and b) do not cover the electrodes, soot can contact the electrodes directly without any limiting serial resistances between electrode and soot. However, the calculated improvements in reduction of the blind time between coatings of $1 \mu \mathrm{m}$ and $20 \mu \mathrm{m}$ thickness as well as with coatings between a resistance of $3 \mathrm{k} \Omega$ and $30 \mathrm{k} \Omega$ (for the data of the sensor with respect to conductivity and film thickness, see Table 1) can be considered insignificant, so that the already mentioned disadvantages of thin layers or low resistance without soot outweigh the slight advantages regarding the current signal. Considering an economical screen printing process, typical layer thicknesses of $5 \mu \mathrm{m}$ or more can be achieved. Hence, a functional layer with an electrical resistance of $30 \mathrm{k} \Omega$ and a thickness of 5 to $20 \mu \mathrm{m}$ seems to be a good tradeoff between improved measurement duration, manufacturability and usability of inexpensive measurement equipment.

\section{Experimental verification}

In Sect. 2, the advantages of a conductive layer were worked out using simulation. In this section, we will describe experimental results and compare them with our simulations.

\section{Experiments}

For this study, the platinum IDEs were screen-printed on alumina film-covered yttria stabilized zirconia (YSZ) substrates. Due to the setup in planar tape technology, a heater could be integrated into the YSZ monolithic substrate. Further details can be obtained from Ochs et al. (2012). 


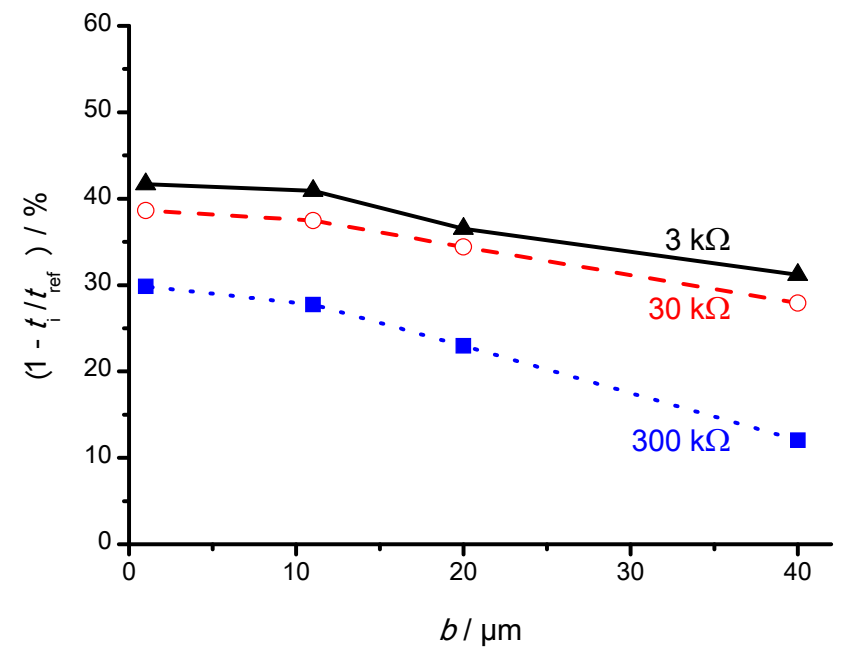

Figure 7. Simulated percentaged reduction of the initiation time $t_{\mathrm{i}}$ for different layer thicknesses and conductivities, see Table 1. $t_{\text {ref }}$ is the initiation time of the uncoated sensor.

Figure 8 shows a typical IDE (without additional coating) during electrophoretic soot deposition. Electrically conductive soot paths grow from one electrode to the other, resulting in an ohmic current (Ochs et al., 2012; Hagen et al., 2010). The initiation time, $t_{\mathrm{i}}$, i.e., the time the current needs to reach a trigger limit (for instance a current of $3 \mu \mathrm{A}$ ) can be used as a measure for the amount of PM in the exhaust gas. After a deposition cycle, the sensor is heated to above $600^{\circ} \mathrm{C}$ to burn the soot on the IDE. After cooling, the sensor is regenerated and the subsequent loading cycle can start.

To verify the results from the simulation and to proof the concept of improving the particle sensor by applying a conductive layer, a commercial resistor paste which is typically used in LTCC and thick-film technology, was applied (Heraeus, type R8281). It consists of $\mathrm{RuO}_{2}$ embedded in a glass matrix (for literature see, e.g., Pike and Seager, 1977, or Nicoloso et al., 1995). The nominal square resistance according to the data sheet was $100 \mathrm{M} \Omega$ for a fired film thickness of $22 \mu \mathrm{m}$. This leads to a conductivity of $0.45 \mathrm{mS} \mathrm{m}^{-1}$, which is close to the optimum determined in the simulation. For the test sensor, this small deviation is not important, because even for a slightly deviating electrical conductivity, the reduction of the initiation time should be significant. It should be clarified that $\mathrm{RuO}_{2}$ embedded is a glass matrix is a good fabrication approach for thick-film resistors in electronics but it is not suitable to be applied in automotive exhausts at elevated temperatures. It is known that $\mathrm{RuO}_{2}$-based materials show reversible as well as irreversible changes in resistance, depending on temperature, mechanical stress and electrical field (Pike and Seager, 1977). Since the temperature during regeneration can reach or even exceed the firing temperature of the $\mathrm{RuO}_{2} /$ glass layer, the glass matrix may soften each time the soot is burned off at regeneration temperatures. This may result in plastic deformation of the conductive layer that

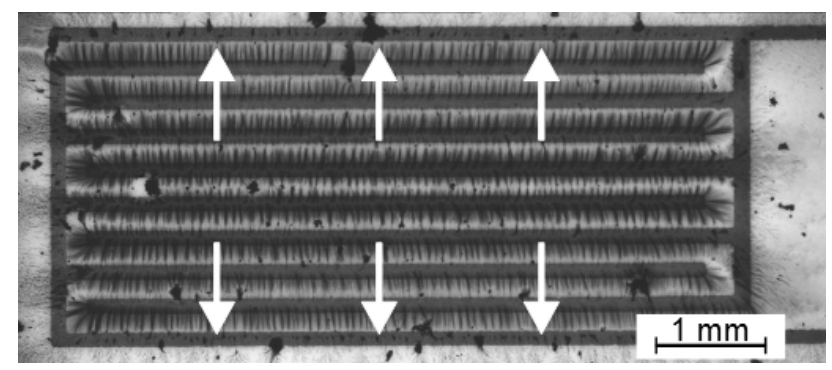

Figure 8. Light optical microscope image of a soot loaded interdigital electrode structure. The soot accumulates in form of percolation paths, growing from one electrode to the other. Exhaust gas hits the sensor perpendicular to the surface and spreads as indicated by the arrows.

changes the electrical characteristic. Furthermore, high temperatures may affect the conductivity of $\mathrm{RuO}_{2}$ due to oxidation and loss of volatile reaction products (Colomer and Jurado, 1997). All these factors affect the conductivity of $\mathrm{RuO}_{2}$-based resistor pastes and may lead to a drift of the sensor current that is not tolerable for a sensor that should operate for many years in the exhaust gas. However, in order to verify the concept, these shortcomings are not relevant and the already mentioned paste was selected despite all its disadvantages.

For the test sample, blank sensors were manufactured as described briefly above and in detail in Ochs et al. (2012). Some of the sensors were coated with the screen-printed paste, dried for $10 \mathrm{~min}$ at $80^{\circ} \mathrm{C}$ and fired at $850{ }^{\circ} \mathrm{C}$ according to the manufacturer's specifications. A fired film thickness of about $35 \mu \mathrm{m}$ was obtained. The sensors were built into the exhaust pipe of an artificial soot source (CAST2, Matter Engineering) together with an uncoated blank sensor serving as a reference. The gas stream was $5 \mathrm{~L} \mathrm{~min}^{-1}$ with an average particle size of $85 \mathrm{~nm}$. During soot deposition, the sensors were not heated, i.e. soot collection occurred at about $35^{\circ} \mathrm{C}$.

Figure 9 shows a typical measuring cycle. At $t_{1}$, the IDE voltage $(30 \mathrm{~V} \mathrm{dc})$ was applied to determine a possible temperature-based drift of the sensor base signal. At $t_{2}$, about 2 min later, the artificial soot source was switched on. After the current of both sensors (coated sensor and blank sensor) exceeded the triggering limit $(3 \mu \mathrm{A})$ significantly, the artificial soot source was switched off at $t_{3}$. At $t_{4}$, the IDE voltage was also switched off and shortly after that, the regeneration was initiated (at $t_{5}$ ). Using the applied heater, a temperature above $750^{\circ} \mathrm{C}$ was achieved and the collected soot was oxidized. After turning off the sensor heating at $t_{6}$, the sensor was allowed to cool down to a stable temperature before the subsequent cycle started.

The raw signal of a coated and an uncoated, blank sensor is shown in Fig. 10. Due to the reasons mentioned above, the coated sensors showed a baseline drift even if no soot was present. A linear extrapolation of the drift (line A in Fig. 10) 


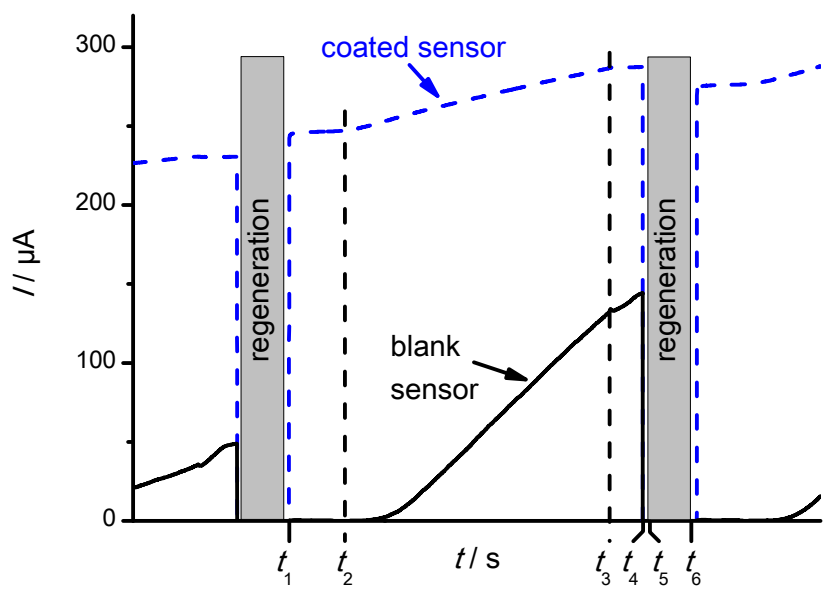

Figure 9. Typical measurement and regeneration cycle. $t_{1}$ : sensor voltage over the IDE is applied, $t_{2}$ : artificial soot source is switched on, $t_{3}$ : artificial soot source is switched off, $t_{4}$ : sensor voltage is switched off, $t_{5}$ to $t_{6}$ : heater current for regeneration is applied.

yielded an increasing baseline. It was used to correct the initiation time $t_{\mathrm{c}}$ as depicted in Fig. 10. The coated sensor showed a baseline of almost $300 \mu \mathrm{A}$, which is equivalent to a resistance of about $100 \mathrm{k} \Omega$ in the soot-free state. Furthermore, the coated sensor reached the trigger limit of $\Delta I \approx 3 \mu \mathrm{A}$ about 100 s earlier than the uncoated sensor, and, as predicted from the simulations, the coated sensor showed a smaller slope $\mathrm{d} I / \mathrm{d} t$. This behavior can be explained by the serial resistance of the conductive coating that reduces the contribution of the soot to the total current.

The very low (but not zero) current of the reference sensor before applying the soot source may originate from some soot that had been deposited between the feed lines during antecedent cycles (see Fig. 1). Since the sensor feeds are not heated, this part was not regenerated. However, this leakage current can be neglected.

The tests were repeated with five different sensors with 1 to 5 cycles for each sensor. The results for each sensor with the standard deviation of the percentaged reduction of the initiation time are shown in Fig. 11. Despite not being optimized, the initiation time with a conductive layer can be reduced by between 25 and $50 \%$ compared to the uncoated sensor. The results are even slightly better than predicted by the simulations ( 25 to $40 \%$ ).

\section{Concluding remarks}

The simulations showed that the conductivity of a conductive coating of the electrode area of a PM sensor greatly influences the sensor performance. Conductivity and layer thickness can be further optimized. On the one hand, higher conductivities are preferred because they reduce the current through the serially connected soot only a little. However, the benefit of a high conductivity gets smaller for higher conduc-

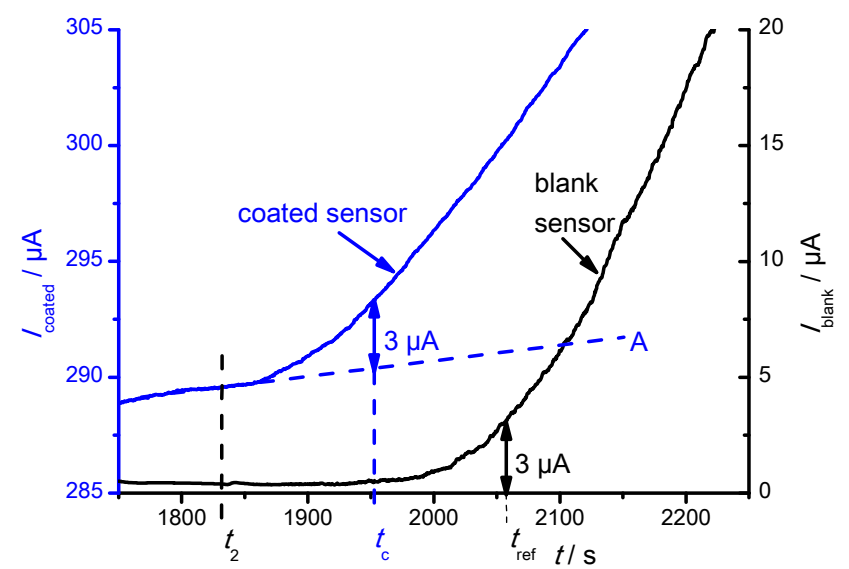

Figure 10. Raw signal for a coated (left axis) and an uncoated (right axis) sensor. The current drift for the coated sensor was compensated using linear extrapolation. The artificial soot source is switched on at $t_{2}$. The coated sensor reaches the trigger limit of $3 \mu \mathrm{A}$ at $t_{\mathrm{c}}$, the uncoated sensor reaches the trigger limit at $t_{\text {ref }}$.

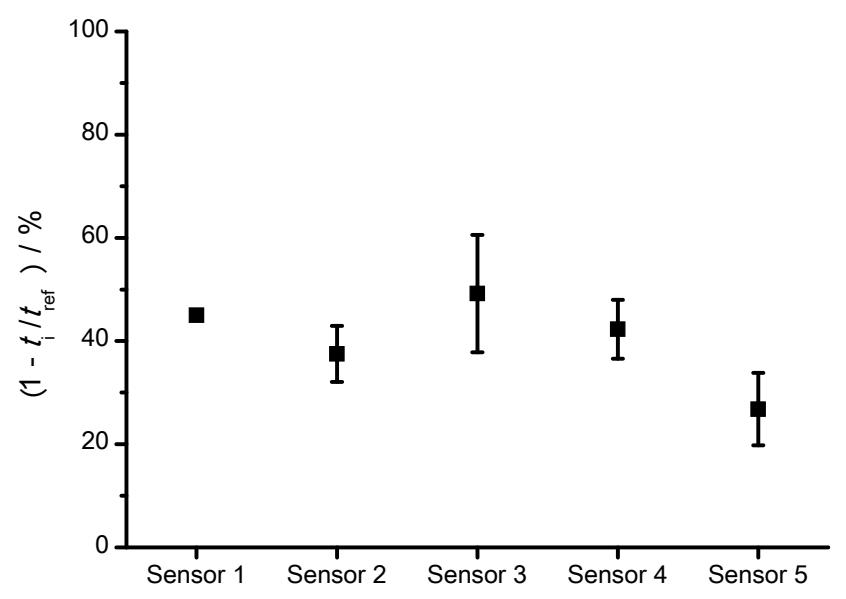

Figure 11. Reduction of the initiation time due to coating, proven for five different sensors.

tivities. Comparing the simulated low and medium conducting layers, an improvement of the initiation time of about $12 \%$ can be obtained with a conductivity change of a factor of 10 . Increasing further the conductivity of the layer by a factor of 10 yields an additional reduction of only about $2 \%$.

Besides the sensor performance with respect to a shorter initiation time, system aspects as well as manufacturing process issues deserve consideration. How can such a conductive coating be applied, what electronic measurement equipment is needed? Both aspects may limit the application.

The conductive layers are preferably applied in thick-film technology. This technique is process compatible, inexpensive and well-known for ceramic exhaust gas sensors (Riegel et al., 2002). Layer thicknesses between about 5 to $50 \mu \mathrm{m}$ can be manufactured reliably. Thin film techniques like CVD or PVD are more expensive and are not preferred. 
Cost issues of the measurement circuit play a crucial role. The higher the required resolution, the more expensive it will $\mathrm{be}^{1}$. If the conductivity of the layer is too high, a 12 bit A/D converter may not be sufficient due to the high base current without soot. In case of the highly conducting coating, a resolution of 15 bit would be needed. For the medium conductivity, 12 bit would be sufficient and for the lowest conductivity 9 bit would suffice. With respect to the required resolution, a low conductivity would be preferable.

As a tradeoff, medium conductive layers are considered best. The demands on the A/D converters are moderate, and the initiation time is short. A higher conductivity does not show a huge advantage regarding the initiation time, but will result in much higher cost of the measuring equipment. A material with an electrical conductivity of $10^{-3}$ to $10^{-1} \mathrm{~S} \mathrm{~m}^{-1}$ would be suitable for a functional layer of $20 \mu \mathrm{m}$ thickness and 12 bit resolution.

The functional demonstration with a $\mathrm{RuO}_{2}$-based coating showed even more potential to reduce the initiation time than expected from the simulation. But it also showed the current limiting effect of a serial connection between soot and functional coating. With a reduction of the initiation time of about $45 \%$ with a non-optimized system, an even higher effect can be expected by using an optimized material and coating, therefore a continuation of these investigations seems promising.

A reduction in the initiation time enhances the accuracy of the sensor and therefore allows a much better prediction of the particle filter condition, meaning that smaller defects may be more reliably detected. However, it is challenging to find a material with a suitable electrical conductivity and the robustness to withstand the harsh conditions in automotive exhausts.

Recently, dosimeter-type resistive gas sensors are suggested for gas concentration measurements (Geupel et al., 2010; Groß et al., 2012). Both soot sensor and dosimeter-type resistive gas sensor rely on the same principle: with sorption of gas (or soot) the resistance changes and as soon as saturation effects occur, sensor regeneration is required, typically induced by heating the sensitive film far above working temperature. Recently, Hennemann et al. (2012), even suggested a dosimeter-type gas sensor based on percolation effects. $\mathrm{H}_{2} \mathrm{~S}$ percolation paths are formed on nanofibers leading to a steep resistance decrease when a defined dose is applied. This behavior is very similar to the conductometric soot sensor where a defined amount of soot yields a similar behavior. It is suggested to transfer the idea of a conductive layer

\footnotetext{
${ }^{1}$ If one accepts a resolution for the $\mathrm{A} / \mathrm{D}$ converter of $12 \mathrm{bit}$, than the measuring range can be resolved in $2^{12}=4096$ equidistant steps. The steps should be about 10 times smaller than the value to be measured. Hence, a trigger limit of $3 \mathrm{~A}$ requires steps of at least $0.3 \mu \mathrm{A}$. If the layer conductivity is too high, a 12 bit A/D converter may not be sufficient due to the high base current without soot.
}

also to such percolation-type conductometric dosimeter gas sensors.

Acknowledgements. The authors thank Ralf Schmidt, Frank Rettig and Gerd Teike for discussions and their help on the simulation and model building, as well as Ulrich Hasenkox and Helmut Marx for the support during the measurements. The authors also thank Robert Bosch $\mathrm{GmbH}$, where most of the work have been done, for supporting this work and for the permission to publish the results.

Edited by: A. Lloyd Spetz

Reviewed by: two anonymous referees

\section{References}

Adar, S. D., Klein, R., Klein, B. E. K., Szpiro, A. A., Cotch, M. F., Wong, T. Y., O’Neill, M. S., Shrager, S., Barr, R. G., Siscovick, D. S., Daviglus, M. L., Sampson, P. D., and Kaufman, J. D.: Air Pollution and the Microvasculature: A Cross-Sectional Assessment of In Vivo Retinal Images in the Population-Based Multi-Ethnic Study of Atherosclerosis (MESA), PLOS Med., 7, 1-11, 2010.

Alkemade, U. G. and Schumann, B.: Engines and exhaust after treatment systems for future automotive applications, Solid State Ionics, 177, 2291-2296, 2006.

Bartscherer, P. and Schmidt, R.: Sensor and method for detecting particles in a gas flow, Patent Application WO002008138659A1, 2008.

Bartscherer, P., Grabis, J., and Schmidt, R.: Verfahren zum Betrieb eines Partikelsensors, German Patent Application DE102007060939A1, 2007.

Bartscherer, P., Hasenkox, U., and Roesch, S.: Sensor for resistively determining concentrations of conductive particles in gas mixtures, Patent Application WO002008025602A1, 2008.

Colomer, M. T. and Jurado, J. R.: Preparation and characterization of gels of the $\mathrm{ZrO}_{2}-\mathrm{Y}_{2} \mathrm{O}_{3}-\mathrm{RuO}_{2}$ system, J. Non-Cryst. Solids, 217, 48-54, 1997.

Duvinage, F., Nolte, A., Paule, M., Schommers, J., and Brueggemann, H.: Dieselpartikelfilter für PKW - gestern, heute und morgen, 10. Aachener Kolloquium Fahrzeug- und Motorentechnik, 2001.

Europäisches Parlament: Verordnung (EG) Nr. 715/2007 über die Typgenehmigung von Kraftfahrzeugen hinsichtlich der Emissionen von leichten Personenkraftwagen und Nutzfahrzeugen (Euro 5 und Euro 6) und über den Zugang zu Reparaturund Wartungsinformationen für Fahrzeuge, Amtsblatt der Europäischen Union, L171, 1-16, 2007.

European Union: Communication on the application and future development of Community legislation concerning vehicle emissions from light-duty vehicles and access to repair and maintenance information (Euro 5 and 6), Official Journal of the European Union, 2008/C 182/08, 2008.

Evans, B. D.: A review of the optical properties of anion lattice vacancies, and electrical conduction in $\mathrm{Al}_{2} \mathrm{O}_{3}$ : their relation to radiation-induced electrical degradation, J. Nucl. Mater., 219, 202-223, 1995. 
Feulner, M., Hagen, G., Piontkowski, A., Müller, A., Fischerauer, G., Brüggemann, D., and Moos, R.: In-Operation Monitoring of the Soot Load of Diesel Particulate Filters - Initial Tests, Top. Catal., 56, 483-488, 2013.

Fischerauer, G., Förster, M., and Moos, R.: Sensing the Soot Load in Automotive Diesel Particulate Filters by Microwave Methods, Meas. Sci. Technol., 21, 035108, doi:10.1088/09570233/21/3/035108, 2010.

Fino, D.: Diesel emission control: Catalytic filters for particulate removal, Sci. Technol. Adv. Mat., 8, 93-100, 2007.

Geiser, M.: Distribution and Clearance of Inhaled Ultrafine $\mathrm{TiO}_{2}$ Particles in Rat Lungs, 9th ETH Conference on CGP, 2005.

Geupel, A., Schönauer, D., Röder-Roith, U., Kubinski, D. J., Mulla, S., Ballinger, T. H., Chen, H.-Y., Visser, J. H., and Moos, R.: Integrating nitrogen oxide sensor: a novel concept for measuring low concentrations in the exhaust gas, Sensor. Actuat. B-Chem., $145,756-761,2010$.

Grahame, T. J. and Schlesinger, R. B.: Cardiovascular Health and Particulate Vehicular Emissions: a Critical evaluation of the Evidence, Air Quality, Atmosphere and Health, 3, 3-27, 2010.

Grob, B., Schmid, J., Ivleva, N., and Niessner, R.: Conductivity for Soot Sensing: Possibilities and Limitations, Anal. Chem., 84, 3586-3592, 2012.

Groß, A., Beulertz, G., Marr, I., Kubinski, D. J., Visser, J. H., and Moos, R.: Dual Mode $\mathrm{NO}_{\mathrm{x}}$ Sensor: Measuring Both the Accumulated Amount and Instantaneous Level at Low Concentrations, Sensors, 12, 2831-2850, 2012.

Hagen, G., Feistkorn, C., Wiegärtner, S., Heinrich, A., Brüggemann, D., and Moos, R.: Conductometric Soot Sensor for Automotive Exhausts: Initial Studies, Sensors, 10, 1589-1598, 2010.

Harris, S. J. and Maricq, M. M.: Signature size distributions for diesel and gasoline engine exhaust particulate matter, Aerosol Science, 32, 749-764, 2001.

Hennemann, J., Sauerwald, T., Kohl, C.-D., Wagner, T., Bognitzki, M., and Greiner, A.: Electrospun copper oxide nanofibers for $\mathrm{H}_{2} \mathrm{~S}$ dosimetry, Phys. Status Solidi A, 209, 911-916, 2012

Johnson, T. V.: Diesel emission control in review, SAE Paper $2007-$ 01-0233, doi:10.4271/2007-01-0233, 2007.

Lloyd Spetz, A., Huotari, J., Bur, C., Bjorklund, R., Lappalainen, J., Jantunen, H., Schütze, A., and Andersson, M.: Chemical sensor systems for emission control from combustions, Sensor. Actuat. B-Chem., doi:10.1016/j.snb.2012.10.078, in press, 2012.
Moos, R., Beulertz, G., Reiß, S., Hagen, G., Fischerauer, G., Votsmeier, M., and Gieshoff, J.: Overview: Status of the microwave-based automotive catalyst state diagnosis, Top. Catal., 56, 358-364, 2013.

Nicoloso, N., LeCorre-Frisch, A., Maier J., and Brook, R. J.: Conduction mechanisms in $\mathrm{RuO}_{2}$-glass composites, Solid State Ionics, 75, 211-216, 1995.

Ochs, T., Schittenhelm, A., Genssle, A., and Kamp, B.: Particulate Matter Sensor for On Board Diagnostics (OBD) of Diesel Particulate Filters (DPF), SAE paper 2010-01-0307, doi:10.4271/2010-01-0307, 2010.

Otto, K., Sieg, M. H., and Zinbo, M.: The Oxidation of Soot Deposits from Diesel Engines, SAE paper 800336, doi:10.4271/800336, 1980.

Pike, G. E. and Seager, C. H.: Electrical properties and conduction mechanisms of Ru-based thick-film (cermet) resistors, J. Appl. Phys., 48, 5152-5169, 1977.

Riegel, J. and Klett, S.: Sensors for modern exhaust gas aftertreatment systems. In: Proceedings of the 5th International Exhaust Gas and Particulate Emissions Forum, Ludwigsburg, Germany, February 2008, 84-97, 2008.

Riegel, J., Neumann, H., and Wiedenmann, H.-M.: Exhaust gas sensors for automotive emission control, Solid State Ionics, 152153, 783-800, 2002.

Rose, D. and Boger, T.: Different Approaches to Soot Estimation as Key Requirement for DPF Applications, SAE paper 2009-011262, doi:10.4271/2009-01-1262, 2009.

Spears, M.: Particulate Matter and Adsorption: The First $100 \mathrm{Sec}-$ onds, 5. Internationales Forum Abgas- und Partikelmesstechnik, Ludwigsburg 2008.

Twigg, M. V.: Progress and future challenges in controlling automotive exhaust gas emissions, Appl. Catal. B-Environ., 70, 2-15, 2007.

Twigg, M. V. and Phillips, P. R. Cleaning the air we breathe - Controlling diesel particulate emissions from passenger cars, Platinum Metals Review, 53, 27-34, 2009.

U.S. Environmental Protection Agency (EPA): Health assessment document for diesel engine exhaust, EPA/600/8-90/057F, 2002. 